\title{
O SABER PROFISSIONAL DO PROFESSOR QUE ENSINA MATEMÁTICA: CONSIDERAÇÕES TEÓRICO-METODOLÓGICAS
}

\author{
Eliene Barbosa Lima ${ }^{1}$ \\ Wagner Rodrigues Valente ${ }^{2}$
}

\begin{abstract}
RESUMO: Neste artigo, analisamos uma possibilidade teórico-metodológica para uma historiografia que trata dos processos de profissionalização dos professores que ensinariam matemática em diversos contextos brasileiros. Em específico, tratamos dos saberes a ensinar e saberes para ensinar, os quais vêm sendo mobilizados pelo GHEMAT para teorizar sobre uma matemática a ensinar e matemática para ensinar, que podem ser estabelecidas a depender das interrogações do pesquisador, consoante com o aparato teórico-metodológico escolhido. Consideramos que tal opção como possível, mediante a um crescente diálogo do historiador da educação matemática com a História Cultural.
\end{abstract}

Palavras-chave: Saberes docentes. Matemática. Historiografia.

\section{THE PROFESSIONAL KNOWLEDGE OF THE TEACHER THAT TEACHES MATHEMATICS: THEORETICAL-METHODOLOGICAL CONSIDERATIONS}

\begin{abstract}
In this article we analyze a theoretical-methodological possibility for a historiography that deals with the processes of professionalization of teachers who would teach mathematics in diverse Brazilian contexts. Specifically, we deal with knowledge to teach and knowledge for teaching, which have been mobilized by GHEMAT to theorize about a mathematics to teach and mathematics for teach, that can be established depending on the questions of the researcher, according to the theoretical- methodological approach. We consider such an option as possible, through a growing dialogue between the historian of mathematical education and Cultural History.
\end{abstract}

Keywords: Teaching knowledge. Mathematics. Historiography.

\footnotetext{
1Doutora em Ensino, Filosofia e História das Ciências. Docente na Universidade Estadual de Feira de Santana (UEFS). Feira de Santana-BA/Brasil. E-mail: elienebarbosalima@gmail.com

2 Doutor em Educação. Livre Docente no Departamento de Educação da Universidade Federal de São Paulo (Unifesp). São Paulo-SP/Brasil. E-mail: ghemat.contato@gmail.com
} 


\section{EL SABER PROFESIONAL DEL PROFESOR QUE ENSEÑA MATEMÁTICA: CONSIDERACIONES TEÓRICO-METODOLÓGICAS}

RESUMEN: En este artículo analizamos una posibilidad teórico-metodológica para una historiografía que trata de los procesos de profesionalización de los profesores que enseñan matemáticas en diversos contextos brasileños. En concreto, tratamos de los saberes a enseñar y saber para enseñar, los cuales están siendo movilizados por el GHEMAT para teorizar sobre matemáticas a enseñar y matemáticas para enseñar, que pueden ser establecidas a depender de las interrogaciones del investigador, según el aparato teórico- metodológico elegido. Consideramos tal opción como posible, mediante un creciente diálogo del historiador de la educación matemática con la Historia Cultural

Palabras clave: Saberes docentes. Matemáticas. Historiografía.

No Brasil, desde o Império, paulatinamente, os elementos básicos para ser professor foram sendo transformados na medida em que a população brasileira começou a florescer como uma sociedade marcada por uma busca de uma nacionalidade, tendo a educação como um fator imprescindível para a sua civilização, o seu progresso e modernização. Começam, então, a ser instituídas uma série de leis, reformas e normatizações educacionais, em particular, para formar o professor em instituições oficiais criadas pelos governos da Monarquia ou da República para esse fim específico.

Assim, essa formação, passou a ter, cada vez mais, rituais próprios com permanências e mudanças, isto é, sem uma estrutura fixa e predeterminada, os quais contribuíram para a constituição de um campo profissional autônomo, ainda que heterogêneo, tanto nos níveis de ensino que foram sendo estabelecidos ao longo do tempo, como na legitimação da prática do professor dito leigo, mesmo sendo muitas vezes chamado apenas de regente, para evidenciar, por certo, em contraste, o status do professor diplomado. Dessa forma, sem nenhuma intenção de demarcar uma identidade homogênea e universal, ser professor, parametrizando nas ideias de Dias (2002), passou a transcender a ideia da bossa, relacionada a uma mera aptidão natural, para a construção de uma jurisdição profissional. Algo que foi primordial no âmbito dos processos de profissionalização docente, institucionalizados socialmente, entre disputas e conflitos pelo seu monopólio, por políticas públicas educacionais de uma dada época. 
De fato, olhando especificamente para o professor que ensinaria e/ou já ensinava matemática, Garnica (2013) afirmou que a formação desse professor, sem negar os movimentos de uma profissionalização, foi variável em diversos cantos do Brasil, em seus mais variados contextos de sua imensidão territorial. Nesse sentido, argumentou que houve, e ainda há, uma multiplicidade de formas, mecanismos e instâncias que legitimaram e aparelharam esse professor no exercício da sua profissão. Nas próprias palavras de Garnica.

\begin{abstract}
A imensidão das terras, a diversidade das culturas e a pluralidade das gentes desempenham papel fundamental nesse mapeamento (referindo-se à pesquisa citada anteriormente): desconsiderar essa variação imensa seria negar a disposição de enfrentar os cenários imensos, diversos, plurais, disformes - nos quais transitam os professores que ensinam Matemática (GARNICA, 2013, p. 44).
\end{abstract}

Isso quer dizer que, por exemplo, se por um lado havia instâncias como as instituições de nível superior com cursos de licenciaturas em matemática e as escolas normais, por outro, existiam estratégias alternativas para conferir registros ao professor que já ensinava matemática em nível secundário, mas que não tinha licenciatura; este foi o caso, por exemplo, da Campanha de Aperfeiçoamento e Difusão do Ensino Secundário (CADES) ${ }^{3}$, criada em 1953, no governo de Getúlio Dorneles Vargas. Essa interpretação ganha ressonância quando examinamos com Larson (2013) alguns aspectos de sua análise sociológica sobre a constituição das profissões em países como Estados Unidos, Inglaterra e França. Nesse sentido, a autora afirmou, parafraseando David Sciulli: "I do not believe that there can be a general theory of professions for all places and all times" (LARSON, 2013, p. xxii).

Contudo, em concordância com Larson (2013), consideramos que esses processos de profissionalização docente, mesmo sendo construídos historicamente por uma pluralidade de variáveis móveis, flexíveis e não desprezíveis, parecem também ser constituídos por alguns outros atributos de dimensões mais gerais, comuns em diversos tempos históricos, independentemente da especificidade da profissão. É o que indicaram as pesquisas da própria

3 Mais informações, veja: (OLIVEIRA; PIETROPAOLO, 2008; BARALDI; GAERTNER, 2010).

4 "Eu não acredito que possa haver uma teoria geral das profissões para todos os lugares e em todos os tempos" (tradução nossa). 
Larson (2013), em um universo mais amplo das profissões e de Nóvoa (1999), em particular, sobre a profissionalização docente. Sob essa ótica, esses autores, guardadas as devidas peculiaridades de suas respectivas pesquisas, apresentaram que fazia parte dos processos de profissionalização uma organização em associações de um corpo de profissionais, os quais compartilhavam, entre si, certo sistema de conhecimentos, de técnicas, de novas competências e de normas éticas para autorregulação e o monopólio da profissão, bem como a criação de novos espaços de formação.

Um dos elementos que parece dar um caráter distintivo às profissões, refere-se à constituição progressiva de saberes próprios para o exercício profissional. Assim, dentre as dimensões mais gerais dos processos de profissionalização, optamos focar o nosso olhar para os saberes profissionais vinculados a uma docência formalizada, a partir de uma análise crítica de alguns textos que tratam de tais saberes. O objetivo foi trazer algumas possibilidades de diálogos teórico-metodológicos para uma historiografia que trata dos processos de profissionalização dos professores que ensinariam matemática em diversos contextos brasileiros.

\section{À guisa de uma historiografia da formação de um professor que ensinaria matemática}

Recentemente, ainda que não seja consensual, é cada vez mais crescente entre os historiadores que lidam com a matemática e o seu ensino se apropriarem de um modus operandi do campo da história, mais notadamente, de uma história cultural produzida por uma pluralidade de abordagens, de objetos e temas, a qual emergiu na década de 1980, rejeitando conceitos da história das ideias. De fato, o que se tem, no desenvolvimento da historiografia é uma ultrapassagem dessa história para aquela das mentalidades. Com ela, novos objetos tomam a cena como o medo, a morte, o pudor, a sexualidade, as crenças e rituais coletivos etc. Assim, a história das mentalidades privilegia mecanismos inconscientes, impessoais e automáticos das práticas sociais. A crítica a esse modo de escrita da história, com o desenvolvimento de uma história das representações (Roger Chartier) permite que sejam 
possíveis estudos mais qualitativos relativamente àqueles seriais trazidos pela história das mentalidades, em que o sujeito estava colocado em segundo plano, sem que fosse possível a análise de apropriações individuais de processos coletivos de produção de sentidos (OFFENSTADT, 2004).

Nessa quebra de hegemonia de um único e grande modelo de fazer história, constituiuse, ainda, uma mudança na relação do historiador com as fontes históricas, as quais eram tomadas como uma verdade inquestionável, sendo apenas descritas pelos historiadores. Nessa nova conjuntura, conforme Vieira, Peixoto e Khoury (2002) e Barros (2004), as fontes históricas já não falam mais por si, mas, por meio das interrogações do próprio historiador, as quais, decorrem, segundo Cardoso (1987, p. 47) apoiando-se em Marc Bloch - um historiador da primeira geração dos Annales - "[...] da cultura histórica do pesquisador, da sua base teórica, de mil conhecimentos externos àquele documento com que estiver trabalhando no momento".

Tal perspectiva já vinha sendo apropriada no âmbito de uma historiografia das ciências, a partir da segunda metade dos anos de 1980, e de uma historiografia da educação, nos anos de 1990. Sob esse olhar mais amplo em produzir pesquisas, alguns historiadores que lidam com a matemática e com o seu ensino não estão se furtando, assim como aconteceu com uma historiografia da história a partir da década de 1920, em estabelecer diálogos profícuos com outras ciências humanas, tais como a antropologia, a psicologia, a sociologia e com a própria educação, bem como em construir pontes com historiografias das ciências e da educação. Algo imponderável em outros tempos.

É sob essa perspectiva que é possível, por exemplo, dialogar com as investigações desenvolvidas pela Equipe de Pesquisa em História das Ciências da Educação (ERHISE) da Universidade de Genebra acerca dos saberes profissionais na formação do professor, as quais podem trazer novos olhares para uma historiografia sobre os processos de profissionalização do professor que ensinaria matemática. Essa equipe de pesquisadores da Suíça vem produzindo investigações de cunho histórico-social, inspiradas em trabalhos da sociologia, representada por Pierre Bourdieu, e da história das ciências, vinculados à Claude Blanckaert e Dominique Pestre. 
Com essa dupla escolha, buscaram distanciar-se de abordagens que tratam dos saberes na prática, ou seja, da ação do professor, para focarem a sua atenção nos saberes sobre a ação desse professor na formação e no ensino, mas não aqueles ligados ao cotidiano, construídos para resolver problemas e que não são passíveis de serem compreendidos fora do contexto em que ocorreram, os quais chamaram de conhecimento, marcando a diferença com o termo saber. Dessa forma, Hofstetter e Schneuwly (2017, p. 131), pontuaram que:

[...] nós nos distinguimos das abordagens que adotam o ponto de vista da prática e abordam o saber a partir da mobilização no fazer; diferentemente disso, colocamos os saberes formalizados no centro de nossas reflexões, tentando conceitualizar o seu papel nas profissões do ensino e da formação.

Portanto, o ponto central das discussões são nos saberes, ditos objetivados - saberes formalizados - que podem ser postulados a partir da identificação de suas propriedades em um dado período histórico, isto é, como um conjunto, construído historicamente, de enunciados coerentes, despersonalizados, teorizados, passíveis de serem reproduzíveis e que foram legitimados por uma comunidade científica e/ou profissional (HOFSTETTER; SCHNEUWLY, 2017). Ainda tornando mais precisa a noção de saber objetivado, cite-se Barbier (2014, p. 9; tradução livre).

[...] os saberes objetivados podem ser definidos como enunciados proposicionais, sujeitos a objetos de julgamento social que vão lhe dar registro de verdade ou de eficácia. Eles podem mesmo ser considerados duplamente como a seguir: de uma parte formaliza uma representação do real (diz algo sobre a realidade), de outra parte enuncia uma correspondência, um link entre essa representação e o objeto representado (a noção de verdade e a afirmação dessa correspondência).

A partir dessa caracterização dos saberes objetivados, Hofstetter e Schneuwly (2017) explicitam dois tipos de saberes de natureza diferente, porém, articulados: aqueles presentes no ensino e os da formação do professor, denominados de saberes a ensinar e saberes para ensinar, definidos a partir das ideias de Bernard Rey sobre os sistemas curriculares constituídos nas mais variadas formações profissionais. Nele, Rey, conforme Hofstetter e Schneuwly (2017), advogou que a construção dos saberes profissionais organizada em um 
currículo deve ser distanciada da prática. Sob essa ótica, definiram que os saberes a ensinar são os objetos do ensino e da formação do professor e, por sua vez, os saberes para ensinar se traduziriam em suas ferramentas de trabalho, para o ensino e para a formação (HOFSTETTER; SCHNEUWLY, 2017). Uma definição que foi um pouco mais detalhada por Valérie Lussi Borer (2017), quando analisou, na Suíça romanda, as dinâmicas de constituição dos saberes no âmbito dos programas de formação de professores voltados tanto para o ensino primário, como para o secundário, interessando-se pela maneira como estes saberes se articulavam. Isso porque, para essa autora, de um lado estavam:

[...] os saberes constitutivos do campo profissional, no qual a referência é a expertise profissional [saberes profissionais ou saberes para ensinar] e, de outro, os saberes emanados dos campos disciplinares de referência produzidos pelas disciplinas universitárias [saberes disciplinares ou saberes concernentes aos saberes a ensinar] (BORER, 2017, p. 175; grifos do autor).

No entanto, a partir desse excerto, consideramos que uma leitura pontual pode possibilitar interpretações simplistas em relação aos saberes a ensinar e os saberes para ensinar. Primeiro, no sentido que os saberes a ensinar podem ser resumidos em apenas saberes disciplinares ou uma mera listagem de conteúdos, sempre devedores das disciplinas universitárias, contrariamente ao que sinalizaram Hosfstetter e Schneuwly (2017). Em sua síntese afirmaram que:

A escolha dos saberes e a sua transformação em saberes a ensinar é o resultado dos processos complexos que transformam fundamentalmente os saberes a fim de torná-los ensináveis. Esse processo pode até conduzir à criação de saberes próprios às instituições educativas, necessárias a elas para assumirem as suas funções (HOFSTETTER; SCHNEUWLY, 2017, p. 133; grifo do autor).

Um segundo alerta se refere à tendência em tratar os saberes para ensinar como se referissem exclusivamente as metodologias de ensino, desprezando alguns elementos que são evocados na seguinte passagem por Hofstetter e Schneuwly (2017, p. 133-134; grifos do autor)

[...] esses saberes constituem ferramentas de trabalho, neste caso saberes para formar ou saberes para ensinar (por simplificação 
utilizaremos aqui o segundo termo). Tratam-se principalmente de saberes sobre "o objeto" do trabalho de ensino e de formação (sobre os saberes a ensinar e sobre o aluno, o adulto, seus conhecimentos, seu desenvolvimento, as maneiras de aprender etc.), sobre as práticas de ensino (métodos, procedimentos, dispositivos, escolha dos saberes a ensinar, modalidades de organização e de gestão) e sobre a instituição que define o seu campo de atividade profissional (planos de estudos, instruções, finalidades, estruturas administrativas e políticas etc.).

Tal explicitação dos saberes é complementada pela própria Borer (2017) em outro trecho de seu texto já citado anteriormente, a partir dos resultados de sua pesquisa sobre os modelos de formação para o ensino primário nos cantões suíços entre o final do século XIX e a primeira metade do século XX. A autora tratou, mais especificamente, do modelo superior de formação de professores, no contraponto com aquele das escolas normais, em que a formação geral era feita em estabelecimentos de níveis secundários e a formação profissional - estudos pedagógicos - nos espaços de ensino superior. Assim, expôs que:

Nesses estudos pedagógicos, os saberes para ensinar (principalmente os ensinos de pedagogia teórica e prática, de psicologia, de ciências da educação) aos quais se unem ainda todas as didáticas/metodologias das diferentes disciplinas escolares, constituem o essencial das ofertas [...] (BORER, 2017, p. 180; grifo do autor).

Um terceiro, e último ponto, refere-se a uma atenção que deve ser dada na própria mobilização desses saberes em uma investigação histórica. A mobilização desses saberes objetivados tratados anteriormente - saberes a ensinar e saberes para ensinar - está vinculada às instituições formais e a sua explicitação depende das interrogações que porventura poderão ser feitas às fontes históricas. Ainda assim, a sua apropriação não se resume apenas à utilização da definição acerca dos saberes a ensinar e saberes para ensinar de forma estanque e inflexível. Ela, por si só, não dá toda dimensão e complexidade da proposta da equipe suíça. Tal definição, está imbricada, por um lado, com os fatores sociais, econômicos e políticos, que interferem na natureza, especificidades e na lógica das instituições de ensino e de formação do professor de um dado momento, em um determinado contexto. Por outro, sua operacionalização dar-se-á em conjunto com duas outras noções, que 
vêm sendo tratadas no âmbito dos estudos do Grupo de Pesquisa de História da Educação Matemática (GHEMAT). Os pesquisadores desse Grupo cunharam, a partir dos referenciais suíços, as categorias matemática a ensinar e matemática para ensinar.

\section{A matemática a ensinar e a matemática para ensinar}

A apropriação dos estudos do grupo da Universidade de Genebra leva-nos a conjecturar sobre o processo de constituição de uma matemática a ensinar e de uma matemática para ensinar. Terá sentido mobilizar tais categorias para caracterizar o processo de elaboração dos saberes profissionais do professor que ensina matemática? A análise histórica poderá validar tal hipótese teórica.

Escolhidas as referências teóricas anteriores, consideradas necessárias à pesquisa histórica de constituição e transformação dos saberes profissionais, há que se admitir que ela não se mostra, por si só, como suficiente para a condução das investigações. Como, tendo em vista esse posicionamento teórico, poderá ser possível captar o movimento de constituição e transformação dos saberes profissionais do professor que ensina matemática? Que procedimentos de cunho mais estritamente metodológico caberiam ser adotados?

Aqui cabe estabelecer mais uma hipótese de trabalho. A análise do material empírico reforçará ou lançará por terra tal hipótese. Parece-nos razoável admitir que cada tempo histórico-pedagógico estabelece e sedimenta ideários de formação de professores, a partir de lutas de hegemonia para o estabelecimento de saberes considerados como importantes para a formação profissional dos professores, para o seu exercício docente. O estabelecimento desses saberes, por meio de sua circulação e apropriação pelos diferentes atores (pesquisadores, professores, formadores, intelectuais etc.), considerados experts ${ }^{5}$, promove a sua objetivação e busca a sua institucionalização no rol dos saberes para a formação de professores.

5 Constituem-se experts aqueles que se dedicaram com zelo, de maneira sistemática, sobre uma base de saber da profissão docente por ela mesma, em outras palavras, inspetores, professores do ensino primário e do ensino secundário, diretores de escola constituíram-se, no final do século XIX e curso do século XX, em experts em razão de sua expertise profissional, a saber, por conhecerem perfeitamente o ofício docente, por nele se destacarem e serem legitimados (HOFSTETTER et al., 2013).

Argumentos Pró-Educação, Pouso Alegre, v. 4, n. 11, p. 928-943, maio - ago., 2019 
De todo modo, quando nos reportamos à história, à pesquisa histórica, temos a possibilidade de análise do movimento de consolidação e decantação de conhecimentos que, sistematizados, objetivam-se para, então, se tornarem saberes. Temos ainda a possibilidade de verificar embates que tiram de cena dadas convicções estabelecidas, certos saberes que passam a ser considerados ultrapassados e que dão lugar a novas propostas, a novos saberes que intentam figurar na formação profissional dos professores.

Em suma, o uso como hipótese teórica de trabalho das categorias matemática a ensinar e matemática para ensinar parece fazer avançar a compreensão dos movimentos de constituição dos saberes profissionais dos professores, dos saberes profissionais dos professores que ensinam matemática. Isso porque, na nossa compreensão, o estudo dos processos de elaboração da matemática a ensinar e da matemática para ensinar e das dinâmicas que articulam tais saberes coloca em nível de superação as análises que congelam o saber matemático, cercando-o de didáticas especiais que não têm status epistemológico de saber. Faz-nos atentar de modo mais acurado para o movimento de produção e de transformação do saber profissional do professor que ensina matemática. Indica-nos que os denominados saberes pedagógicos, didáticos, representam uma etapa histórica de promoção do reconhecimento da constituição dos saberes profissionais. Avançam para além da ideia de que a formação é somatório de bom conhecimento matemático com didáticas específicas de conteúdos. Apontam para a necessidade de consolidação de rubricas na formação de professores que sejam objetivadas como saberes, saberes para ensinar, matemática para ensinar.

As hipóteses teóricas para o desenvolvimento da pesquisa advogam a existência de tempos históricos diferentes, com concepções próprias sobre formação de professores, sobre a matemática presente nessa formação, sobre a matemática que será ser ensinada. Noutros termos, a matemática a ensinar e a matemática para ensinar são categorias históricas. Conceitos-chave caracterizados num dado tempo histórico. Possíveis de serem estabelecidos por hipótese de trabalho, serem manejados teórica e metodologicamente tendo em conta a especificidade da formação de professores e da docência, garantida no período abordado pelo projeto. 
O invariante da forma escolar, considerando-se as reflexões postas nos estudos de Hofstetter e Schneuwly (2009), permite considerar que a formação de professores e o ensino escolar, na travessia dos tempos apresenta - e aqui reside o próprio núcleo definidor da forma escolar - "a escola como lugar específico, separado de outras práticas sociais (o exercício da profissão em especial), ligado à existência de saberes objetivados"; "a pedagogização das relações sociais de aprendizagem, inseparável de uma escrituralização-codificação dos saberes e das práticas"; "a sistematização do ensino, produzindo efeitos de socialização duradouros (reprodução social)"; "a escola como lugar de aprendizagem de formas de exercício de poder, mediante normas supra pessoais às quais professores e alunos estão sujeitos"; "a instauração de uma relação escritural-escolar com a linguagem e com o mundo" (HOFSTETTER; SCHNEUWLY, 2009, p. 10-11).

Para todos esses invariantes característicos da forma escolar, ao longo dos tempos, o saber está presente. No primeiro invariante, explicitamente há os "saberes objetivados"; no segundo, "uma escrituralização-codificação dos saberes e práticas"; no terceiro, "a sistematização do saber"; no quarto, "normas supra-pessoais" e, finalmente, "uma relação escritural-escolar". Todos esses elementos remetem aos saberes objetivados.

\section{Uma metodologia para a pesquisa da matemática a ensinar e da matemática para ensinar}

Como se mencionou anteriormente, no âmbito da história cultural, em específico, na pesquisa que centra a atenção na cultura escolar (CHERVEL, 1990) há necessidade de análise de toda uma documentação que possa revelar melhor o estabelecimento de determinados saberes numa dada época. Como tratar a documentação oficial do ensino, os manuais pedagógicos e livros didáticos, as publicações lidas nas revistas pedagógicas sobre o ensino de matemática, os cadernos escolares com aulas de matemática, dentre outros documentos, com o fim de caracterização da matemática a ensinar e da matemática para ensinar? Alguns estudos têm sido recentemente realizados para tentar responder a esse imperativo da pesquisa que tem por objetivo caracterizar o saber profissional do professor que ensina 
matemática.

A resposta a tal questão nos leva à aproximação de estudos recentemente realizados por Peter Burke. O autor, no livro "What is the History of Knowledge?" (2015) ${ }^{6}$ discute a pertinência de uma história do saber. Tal história conta a trajetória da informação ainda relativamente 'crua' ao saber, algo processado, 'cozido'. Burke anota que uma designação mais formal para esse processo de prova, elaboração e sistematização é a 'cientifização' (BURKE, 2017, p. 44). O livro analisa, desse modo, "o rumo que seguem certas porções de informações quando nelas se descobre, analisa, 'cozinha' ou 'processa' elementos transformando-os em saber" (BURKE, 2017, p. 69).

Noutros termos, a temática da obra leva-nos a refletir sobre como investigar processos de sistematização de informações que levam à constituição dos saberes, a partir dos elementos deixados como rastros de culturas escolares de outros tempos. Em tempo: Burke enfatiza que apesar de as práticas de sistematização parecerem inalteradas ao longo do tempo, na realidade, elas dependem "da conjuntura, ocorrem de acordo com diferentes regras e diferentes tipos de apoio em diferentes épocas e meios" (BURKE, 2017, p. 69). Dito isso, o autor, ilustra o seu texto com uma série de exemplos que mostram a historicidade de cada procedimento, indicados como integrantes das práticas de sistematização. Burke aponta quatro grandes etapas e seus procedimentos, no âmbito das práticas de sistematização: recompilação, análise, disseminação e emprego, etapas que transformam informações dispersas em saber. Tais referências são apropriadas para os objetivos deste texto.

No entanto, antes de prosseguir, cabe reconfigurar a interrogação norteadora destes escritos, a partir desse estudo de Burke. Tal alteração visa dar uma maior precisão à problemática abordada por este artigo, qual seja, da caracterização de uma base teóricometodológica de pesquisa sobre o saber profissional do professor que ensina matemática. Cabe enunciá-la, agora, do seguinte modo: como informações sobre experiências docentes vão sendo transformadas em saber ao longo da história da educação? A questão envolve

\footnotetext{
${ }^{6}$ Utilizamos a tradução editada em 2017, em espanhol, sob título “¿Qué es la historia del conocimiento? Como la información dispersa se ha convertido en saber consolidado a lo largo de la historia".
}

Argumentos Pró-Educação, Pouso Alegre, v. 4, n. 11, p. 928-943, maio - ago., 2019 
reflexões sobre a passagem dos conhecimentos, das experiências didático-pedagógicas dos docentes para a sua sistematização e reconhecimento como um saber, um saber científico do campo pedagógico, que poderá ser utilizado em diferentes contextos da formação de professores e da docência. Tais experiências docentes se realizam parametrizadas por normativas oficiais, por livros e manuais pedagógicos, por meio de revistas pedagógicas que indicam orientações didáticas aos professores para o ensino de matemática, são registradas em cadernos de alunos e professores, explicitam-se em provas e exames de matemática, dentre outros elementos

$\mathrm{Na}$ caracterização dos processos, que levam experiências dos sujeitos a saberes reconhecidos como científicos, tem-se etapas na investigação, marcadas por determinados procedimentos. Por certo, os processos são históricos, mas é possível enunciá-los, tendo em conta as observações de Peter Burke sobre as suas mudanças de conteúdo ao longo do tempo. Assim, na apropriação dos estudos desse autor, aliando-se conhecimentos que já vêm sendo elaborados na execução do projeto temático mencionado anteriormente, é possível considerar etapas como: recompilação de experiências docentes, análise comparativa dos conhecimentos dos docentes, sistematização e uso dos conhecimentos como saberes.

A recompilação de experiências docentes, do modo como estamos entendendo tal procedimento, envolve a seleção e separação de informações relatadas em revistas pedagógicas; organizadas em livros didáticos e manuais pedagógicos; normatizadas em leis do ensino; contidas em documentação pessoal de alunos e professores; materializadas em dispositivos pedagógicos para o ensino dentre outros tipos de documentação passíveis de evidenciar informações sobre o trabalho pedagógico dos professores. O conjunto obtido de tal procedimento de pesquisa representa uma coleção de conhecimentos dispersos num dado tempo histórico. E, aqui, é importante retomar a diferença, em termos teórico-metodológicos, entre conhecimento e saber, do modo como estamos mobilizando este duo conceitual. $\mathrm{O}$ primeiro mais ligado à subjetividade, às experiências vividas pelo sujeito, meios implícitos da ação, do raciocínio; o segundo, fruto de sistematização, de caráter mais consensual, passível de generalização e objetivação, produto cultural historicamente institucionalizado cujo resultado é a sistematização e organização de determinados conhecimentos com o fim de 
propiciar a sua comunicação? .

A análise comparativa dos conhecimentos dos docentes visa promover uma nova seleção no âmbito do inventário elaborado anteriormente, com a montagem da coleção de conhecimentos dispersos num dado tempo da história da educação escolar. Tal seleção envolve um novo inventário, agora composto pela separação daquelas informações sobre experiências docentes que se mostram convergentes do ponto de vista da orientação para o trabalho do professor. Por esse procedimento de pesquisa tem-se a possibilidade de que sejam reveladas tendências de assentamento de propostas e construção de consensos pedagógicos sobre o que deve o professor saber para a realização de seu ofício.

O procedimento de sistematização e análise do uso dos conhecimentos como saberes representa a última etapa do percurso que transforma informações sobre experiências docentes em saber profissional do professor. Sistematização e análise de uso são procedimentos realizados concomitantemente. Assim, cabe ao pesquisador ou grupo de pesquisadores, organizar, a partir da etapa anterior, uma assepsia de elementos subjetivos e conjunturais dos consensos pedagógicos, de modo a que os conhecimentos possam ser vistos com caráter passível de generalização e de uso, isto é, como saber. De outra parte, a análise inclui, de modo conjunto, a verificação em instâncias normativas e/ou didático-pedagógicas da ocorrência de uso dos elementos sistematizados pelo pesquisador. Tais procedimentos indicados para a investigação de como informações dispersas sobre experiências docentes levam ao saber profissional do professor, assim será possível a caracterização da matemática a ensinar e da matemática para ensinar

\section{Considerações finais}

Essas discussões teórico-metodológicas constituem desafio para historiadores que tomam a matemática e o seu ensino como temas de estudo, ao se apropriarem de um modus operandi do historiador, em especial do historiador cultural, que por si só já é pluralizado. De outra parte, não se traduz em uma tarefa trivial desobstruir pontos de vista, escapar de

7 Para uma caracterização mais precisa dos termos "saber" e "conhecimento", leia-se Brousseau (1994). 
armadilhas de uma história descritiva, julgada, internalista e anacrônica para profissionais que não tiveram uma formação inicial em História.

Contudo, consideramos que se render a essas dificuldades, tendo esses contextos plurais de pensar e produzir história, significa abrir mão de uma diversidade de temas, abordagens teóricas e recursos metodológicos diferenciados para captar novos objetos. Exemplo disso, é a profissionalização do professor que ensinaria matemática, tendo como foco a constituição dos saberes profissionais em cada tempo histórico - a partir de novas perspectivas, privilegiando legislações oficiais, cadernos, programas, diários de classes, revistas pedagógicas e livros didáticos, dentre outras fontes históricas.

Foi, portanto, para ampliar ou pelo menos provocar inquietações que trouxemos algumas possibilidades de diálogos teórico-metodológicos para uma historiografia que trata dos processos de profissionalização dos professores que ensinariam matemática em diversos contextos brasileiros. Em específico, sobre as investigações desenvolvidas pela equipe suíça acerca dos saberes profissionais na formação do professor, isto é, saberes a ensinar e saberes para ensinar, os quais vêm sendo mobilizados pelo GHEMAT para teorizar sobre uma matemática a ensinar e matemática para ensinar, que podem ser estabelecidas a depender das interrogações do pesquisador, consoante com um aparato teórico-metodológico escolhido.

\section{Referências}

BARALDI, I. M.; GAERTNER, R. Contribuições da CADES para a Educação (Matemática) Secundária no Brasil: uma descrição da produção bibliográfica (1953-1971). BOLEMA: Boletim de Educação Matemática. Instituto de Geociências e Ciências Exatas, Departamento de Matemática. Rio Claro (SP), v. 23, n. 35A, p. 159-183, abr. 2010.

BARBIER, J. M. Introduction. In: BARBIER, J. M. (org.). Savoirs Théoriques et Savoirs d'Action. Éducation et formation. Paris: Press Universitaires de France. 2014.

BARROS, J. D’A. O campo da história: especialidades e abordagens. Petrópolis: Vozes, 2004.

BROUSSEAU, G. Perspectives pour la Didactique des Mathématiques. In: ARTIGUE, R. et al. (org.). Vingt ans de Didactique des mathématiques en France. Hommage a Guy Brousseau et Gérard Vergnaud. Paris: La Pensée Sauvage, Editions, 1994. p. 51-66.

BORER, V. L. Saberes: uma questão crucial para a institucionalização da formação de 
professores. In: HOFSTETTER, R.; VALENTE, W. R. (org.). Saberes em (trans)formação: tema central da formação de professores. São Paulo: Livraria da Física, 2017. p. 173-199.

BURKE, P. ¿Qué es la historia del conocimiento? Como la información dispersa se ha convertido en saber consolidado a lo largo de la historia. Buenos Aires, Argentina: Siglo Veintiuno, 2017.

CARDOSO, C. F. S. Uma introdução à história. São Paulo: Brasiliense, 1987. Disponível em: https://docero.com.br/doc/1xc1eo. Acesso em: maio de 2019.

CHERVEL, A. História das disciplinas escolares: reflexões sobre um campo de pesquisa. Teoria \& Educação. Porto Alegre, n. 2, p. 177-229, 1990.

DIAS, A. L. M. Da bossa das matemáticas à educação matemática: disputas por uma jurisdição profissional. Revista História \& Educação Matemática, Rio Claro, v. 2, n. 2, p. 191-226, jan./dez. 2002.

GARNICA, A. V. M. Cartografias contemporâneas: mapa e mapeamento como metáforas para a pesquisa sobre a formação de professores de Matemática. ALEXANDRIA - Revista de Educação em Ciência e Tecnologia, Florianópolis, v. 6, n. 1, p. 35-60, abr. 2013. Disponível em: https://periodicos.ufsc.br/index.php/alexandria/article/view/37927. Acesso em: 15 jul. 2018.

HOFSTETTER, R.; SCHNEUWLY. B. Savoirs en (trans)formation: au cœur des professions de l'enseignement et de la formation. Bruxelles: Éditions De Boeck Université, 2009.

HOFSTETTER, R. et al. La Fabrique des savoirs: figures et pratiques d'experts. Genève: Éditions Médicine et Hygiène - Georg, 2013.

HOFSTETTER, R.; SCHNEUWLY, B. Saberes: um tema central para as profissões do ensino e da formação. In: HOFSTETTER, R.; VALENTE, W. R. (org.). Saberes em

(trans)formação: tema central da formação de professores. São Paulo: Livraria da Física, 2017. p. 113-172.

LARSON, M. S. The rise of profissionalism: monopolies of comptence and sheltered markets. Ed. Rev. New Brunswick, New Jersey: Transaction Publishers, 2013.

NÓVOA, A. O passado e o presente dos professores. In: NÓVOA, A. (org.). Profissão professor. 2. ed. Porto: Porto Editora, 1999. p. 13-34.

OFFENSTADT, N. (org.). Les mots de l'historien. Tolouse, France: Press Universitaires du Mirail, 2004.

OLIVEIRA, M. C. A.; PIETROPAOLO, R. C. Traços de 'Modernidade' nos artigos de Matemática da revista Escola Secundária. Revista Diálogo Educacional, Curitiba, v. 8, n. 25, p. 715-726, set./dez. 2008.

VIEIRA, M. P. A.; PEIXOTO, M. R. C.; KHOURY, Y. A. A pesquisa em história. 4. ed. São Paulo: Ática, 2002. 